\title{
A Hybrid Iterative Scheme for Equilibrium Problems, Variational Inequality Problems, and Fixed Point Problems in Banach Spaces
}

\author{
Prasit Cholamjiak \\ School of Science and Technology, Naresuan University at Phayao, Phayao 56000, Thailand \\ Correspondence should be addressed to Prasit Cholamjiak, prasitch2008@yahoo.com \\ Received 5 February 2009; Accepted 10 April 2009 \\ Recommended by Simeon Reich \\ The purpose of this paper is to introduce a new hybrid projection algorithm for finding a \\ common element of the set of solutions of the equilibrium problem and the set of the variational \\ inequality for an inverse-strongly monotone operator and the set of fixed points of relatively quasi- \\ nonexpansive mappings in a Banach space. Then we show a strong convergence theorem. Using \\ this result, we obtain some applications in a Banach space.
}

Copyright (c) 2009 Prasit Cholamjiak. This is an open access article distributed under the Creative Commons Attribution License, which permits unrestricted use, distribution, and reproduction in any medium, provided the original work is properly cited.

\section{Introduction}

Let $E$ be a real Banach space and let $E^{*}$ be the dual of $E$. Let $C$ be a closed convex subset of $E$. Let $A: C \rightarrow E^{*}$ be an operator. The classical variational inequality problem for $A$ is to find $\hat{x} \in C$ such that

$$
\langle A \hat{x}, y-\widehat{x}\rangle \geq 0, \quad \forall y \in C
$$

The set of solutions of (1.1) is denoted by $\operatorname{VI}(A, C)$. Such a problem is connected with the convex minimization problem, the complementarity, the problem of finding a point $\widehat{x} \in E$ satisfying $0=A \widehat{x}$, and so on. First, we recall that

(1) an operator $A$ is called monotone if

$$
\langle A x-A y, x-y\rangle \geq 0, \quad \forall x, y \in C .
$$


(2) an operator $A$ is called $\alpha$-inverse-strongly monotone if there exists a constant $\alpha>0$ with

$$
\langle A x-A y, x-y\rangle \geq \alpha\|A x-A y\|^{2}, \quad \forall x, y \in C .
$$

Assume that

(C1) $A$ is $\alpha$-inverse-strongly monotone,

(C2) $\operatorname{VI}(A, C) \neq \varnothing$,

(C3) $\|A y\| \leq\|A y-A u\|$ for all $y \in C$ and $u \in V I(A, C)$.

Iiduka and Takahashi [1] introduced the following algorithm for finding a solution of the variational inequality for an operator $A$ that satisfies conditions (C1)-(C3) in a 2uniformly convex and uniformly smooth Banach space $E$. For an initial point $x_{1}=x \in C$, define a sequence $\left\{x_{n}\right\}$ by

$$
x_{n+1}=\Pi_{C} J^{-1}\left(J x_{n}-\lambda_{n} A x_{n}\right), \quad \forall n \geq 1,
$$

where $J$ is the duality mapping on $E$, and $\Pi_{C}$ is the generalized projection from $E$ onto C. Assume that $\lambda_{n} \in[a, b]$ for some $a, b$ with $0<a<b<c^{2} \alpha / 2$ where $1 / c$ is the $p$ uniformly convexity constant of $E$. They proved that if $J$ is weakly sequentially continuous, then the sequence $\left\{x_{n}\right\}$ converges weakly to some element $z$ in $\operatorname{VI}(A, C)$ where $z=$ $\lim _{n \rightarrow \infty} \prod_{V I(A, C)}\left(x_{n}\right)$.

The problem of finding a common element of the set of the variational inequalities for monotone mappings in the framework of Hilbert spaces and Banach spaces has been intensively studied by many authors; see, for instance, [2-4] and the references cited therein. Let $f: C \times C \rightarrow R$ be a bifunction. The equilibrium problem for $f$ is to find $\widehat{x} \in C$ such that

$$
f(\widehat{x}, y) \geq 0, \quad \forall y \in C
$$

The set of solutions of (1.5) is denoted by $E P(f)$.

For solving the equilibrium problem, let us assume that a bifunction $f$ satisfies the following conditions:

(A1) $f(x, x)=0$ for all $x \in C$;

(A2) $f$ is monotone, that is, $f(x, y)+f(y, x) \leq 0$ for all $x, y \in C$;

(A3) for all $x, y, z \in C$,

$$
\limsup _{t \downarrow 0} f(t z+(1-t) x, y) \leq f(x, y)
$$

(A4) for all $x \in C, f(x, \cdot)$ is convex and lower semicontinuous. 
Recently, Takahashi and Zembayashi [5], introduced the following iterative scheme which is called the shrinking projection method:

$$
\begin{gathered}
x_{0}=x \in C, \quad C_{0}=C, \\
y_{n}=J^{-1}\left(\alpha_{n} J x_{n}+\left(1-\alpha_{n}\right) J T x_{n}\right), \\
u_{n} \in C \text { such that } f\left(u_{n}, y\right)+\frac{1}{r_{n}}\left\langle y-u_{n}, J u_{n}-J y_{n}\right\rangle \geq 0, \quad \forall y \in C, \\
C_{n+1}=\left\{z \in C_{n}: \phi\left(z, u_{n}\right) \leq \phi\left(z, x_{n}\right)\right\}, \\
x_{n+1}=\Pi_{C_{n+1}} x_{0}, \quad \forall n \geq 0,
\end{gathered}
$$

where $J$ is the duality mapping on $E$ and $\Pi_{C}$ is the generalized projection from $E$ onto $C$. They proved that the sequence $\left\{x_{n}\right\}$ converges strongly to $q=\Pi_{F(T) \cap E P(f)} x_{0}$ under appropriate conditions.

Very recently, Qin et al. [6] extend the iteration process (1.7) from a single relatively nonexpansive mapping to two relatively quasi-nonexpansive mappings:

$$
\begin{gathered}
x_{0} \in E, \text { chosen arbitrarily, } \\
C_{1}=C, \quad x_{1}=\Pi_{C_{1}} x_{0}, \\
y_{n}=J^{-1}\left(\alpha_{n} J x_{n}+\beta_{n} J T x_{n}+\gamma_{n} J S x_{n}\right), \\
u_{n} \in C \quad \text { such that } f\left(u_{n}, y\right)+\frac{1}{r_{n}}\left\langle y-u_{n} J u_{n}-J y_{n}\right\rangle \geq 0, \quad \forall y \in C, \\
C_{n+1}=\left\{z \in C_{n}: \phi\left(z, u_{n}\right) \leq \phi\left(z, x_{n}\right)\right\}, \\
x_{n+1}=\Pi_{C_{n+1}} x_{0} .
\end{gathered}
$$

Under suitable conditions over $\left\{\alpha_{n}\right\},\left\{\beta_{n}\right\}$, and $\left\{\gamma_{n}\right\}$, they obtain that the sequence $\left\{x_{n}\right\}$ generated by (1.8) converges strongly to $q=\prod_{F(T) \cap F(S) \cap E P(f)} x_{0}$.

The problem of finding a common element of the set of fixed points and the set of solutions of an equilibrium problem in the framework of Hilbert spaces and Banach spaces has been studied by many authors; see [5, 7-16].

Motivated by Iiduka and Takahashi [1], Takahashi and Zembayashi [5], and Qin et al. [6], we introduce a new general process for finding common elements of the set of the equilibrium problem and the set of the variational inequality problem for an inversestrongly monotone operator and the set of the fixed points for relatively quasi-nonexpansive mappings. 


\section{Preliminaries}

Let $E$ be a real Banach space and let $U=\{x \in E:\|x\|=1\}$ be the unit sphere of $E$. A Banach space $E$ is said to be strictly convex if for any $x, y \in U$,

$$
x \neq y \quad \text { implies }\left\|\frac{x+y}{2}\right\|<1
$$

It is also said to be uniformly convex if for each $\varepsilon \in(0,2]$, there exists $\delta>0$ such that for any $x, y \in U$,

$$
\|x-y\| \geq \varepsilon \text { implies }\left\|\frac{x+y}{2}\right\|<1-\delta .
$$

It is known that a uniformly convex Banach space is reflexive and strictly convex; and we define a function $\delta:[0,2] \rightarrow[0,1]$ called the modulus of convexity of $E$ as follows:

$$
\delta(\varepsilon)=\inf \left\{1-\left\|\frac{x+y}{2}\right\|: \quad x, y \in E,\|x\|=\|y\|=1,\|x-y\| \geq \varepsilon\right\} .
$$

Then $E$ is uniformly convex if and only if $\delta(\varepsilon)>0$ for all $\varepsilon \in(0,2]$. Let $p$ be a fixed real number with $p \geq 2$. A Banach space $E$ is said to be $p$-uniformly convex if there exists a constant $c>0$ such that $\delta(\varepsilon) \geq c \varepsilon^{p}$ for all $\varepsilon \in[0,2]$; see [17-19] for more details. A Banach space $E$ is said to be smooth if the limit

$$
\lim _{t \rightarrow 0} \frac{\|x+t y\|-\|x\|}{t}
$$

exists for all $x, y \in U$. It is also said to be uniformly smooth if the limit (2.4) is attained uniformly for $x, y \in U$. One should note that no Banach space is $p$-uniformly convex for $1<p<2$; see [19]. It is well known that a Hilbert space is 2-uniformly convex, uniformly smooth. For each $p>1$, the generalized duality mapping $J_{p}: E \rightarrow 2^{E^{*}}$ is defined by

$$
J_{p}(x)=\left\{x^{*} \in E^{*}:\left\langle x, x^{*}\right\rangle=\|x\|^{p},\left\|x^{*}\right\|=\|x\|^{p-1}\right\}
$$

for all $x \in E$. In particular, $J=J_{2}$ is called the normalized duality mapping. If $E$ is a Hilbert space, then $J=I$, where $I$ is the identity mapping. It is also known that if $E$ is uniformly smooth, then $J$ is uniformly norm-to-norm continuous on each bounded subset of $E$. See [20,21] for more details.

Lemma 2.1 (See $[18,22]$ ). Let $p$ be a given real number with $p \geq 2$ and $E$ a $p$-uniformly convex Banach space. Then, for all $x, y \in E, j_{x} \in J_{p}(x)$ and $j_{y} \in J_{p}(y)$,

$$
\left\langle x-y, j_{x}-j_{y}\right\rangle \geq \frac{c^{p}}{2^{p-2} p}\|x-y\|^{p},
$$

where $J_{p}$ is the generalized duality mapping of $E$ and $1 / c$ is the $p$-uniformly convexity constant of $E$. 
Let $E$ be a smooth Banach space. The function $\phi: E \times E \rightarrow R$ is defined by

$$
\phi(x, y)=\|x\|^{2}-2\langle x, J y\rangle+\|y\|^{2}
$$

for all $x, y \in E$. In a Hilbert space $H$, we have $\phi(x, y)=\|x-y\|^{2}$ for all $x, y \in H$.

Recall that a mapping $T: C \rightarrow C$ is called nonexpansive if $\|T x-T y\| \leq\|x-y\|$ for all $x, y \in C$ and relatively nonexpansive if $T$ satisfies the following conditions:

(1) $F(T) \neq \varnothing$, where $F(T)$ is the set of fixed points of $T$;

(2) $\phi(p, T x) \leq \phi(p, x)$ for all $p \in F(T)$ and $x \in C$;

(3) $F(\widehat{T})=F(T)$, where $F(\widehat{T})$ is the set of all asymptotic fixed points of $T$;

see $[10,23,24]$ for more details.

$T$ is said to be relatively quasi-nonexpansive if $T$ satisfies the conditions (1) and (2). It is easy to see that the class of relatively quasi-nonexpansive mappings is more general than the class of relatively nonexpansive mappings $[9,25,26]$.

We give some examples which are closed relatively quasi-nonexpansive; see [6].

Example 2.2. Let $E$ be a uniformly smooth and strictly convex Banach space and $A \subset E \times E^{*}$ be a maximal monotone mapping such that its zero set $A^{-1} 0 \neq \varnothing$. Then, $J_{r}=(J+r A)^{-1} J$ is a closed relatively quasi-nonexpansive mapping from $E$ onto $D(A)$ and $F\left(J_{r}\right)=A^{-1} 0$.

Example 2.3. Let $\Pi_{C}$ be the generalized projection from a smooth, strictly convex, and reflexive Banach space $E$ onto a nonempty closed convex subset $C$ of $E$. Then, $\Pi_{C}$ is a closed relatively quasi-nonexpansive mapping with $F\left(\Pi_{C}\right)=C$.

Lemma 2.4 (Kamimura and Takahashi [27]). Let E be a uniformly convex and smooth Banach space and let $\left\{x_{n}\right\},\left\{y_{n}\right\}$ be two sequences of $E$. If $\phi\left(x_{n}, y_{n}\right) \rightarrow 0$ and either $\left\{x_{n}\right\}$ or $\left\{y_{n}\right\}$ is bounded, then $\left\|x_{n}-y_{n}\right\| \rightarrow 0$ as $n \rightarrow \infty$.

Let $C$ be a nonempty closed convex subset of $E$. If $E$ is reflexive, strictly convex and smooth, then there exists $x_{0} \in C$ such that $\phi\left(x_{0}, x\right)=\min \phi(y, x)$ for $x \in E$ and $y \in C$. The generalized projection $\Pi_{C}: E \rightarrow C$ defined by $\Pi_{C} x=x_{0}$. The existence and uniqueness of the operator $\Pi_{C}$ follows from the properties of the functional $\phi$ and strict monotonicity of the duality mapping $J$; for instance, see $[20,27-30]$. In a Hilbert space, $\Pi_{C}$ is coincident with the metric projection.

Lemma 2.5 (Alber [28]). Let $C$ be a nonempty closed convex subset of a smooth Banach space $E$ and $x \in E$. Then $x_{0}=\Pi_{C} x$ if and only if $\left\langle x_{0}-y, J x-J x_{0}\right\rangle \geq 0$ for all $y \in C$.

Lemma 2.6 (Alber [28]). Let $C$ be a nonempty closed convex subset of a reflexive, strictly convex and smooth Banach space $E$ and let $x \in E$. Then

$$
\phi\left(y, \Pi_{C} x\right)+\phi\left(\Pi_{C} x, x\right) \leq \phi(y, x), \quad \forall y \in C
$$

Lemma 2.7 (Qin et al. [6]). Let E be a uniformly convex, smooth Banach space, let $C$ be a closed convex subset of $E$, let $T$ be a closed and relatively quasi-nonexpansive mapping from $C$ into itself. Then $F(T)$ is a closed convex subset of $C$. 
Lemma 2.8 (Cho et al. [31]). Let $E$ be a uniformly convex Banach space and let $B_{r}(0)$ be a closed ball of $E$. Then there exists a continuous strictly increasing convex function $g:[0, \infty) \rightarrow[0, \infty)$ with $g(0)=0$ such that

$$
\|\alpha x+\beta y+\gamma z\|^{2} \leq \alpha\|x\|^{2}+\beta\|y\|^{2}+\gamma\|z\|^{2}-\alpha \beta g(\|x-y\|),
$$

for all $x, y, z \in B_{r}(0)$, and $\alpha, \beta, \gamma \in[0,1]$ with $\alpha+\beta+\gamma=1$.

Lemma 2.9 (Blum and Oettli [7]). Let $C$ be a closed convex subset of a smooth, strictly convex, and reflexive Banach space $E$, let $f$ be a bifunction from $C \times C$ to $R$ satisfying $(A 1)-(A 4)$, and let $r>0$ and $x \in E$. Then, there exists $z \in C$ such that

$$
f(z, y)+\frac{1}{r}\langle y-z, J z-J x\rangle \geq 0, \quad \forall y \in C
$$

Lemma 2.10 (Qin et al. [6]). Let $C$ be a closed convex subset of a uniformly smooth, strictly convex, and reflexive Banach space $E$, and let $f$ be a bifunction from $C \times C$ to $R$ satisfying (A1)-(A4). For all $r>0$ and $x \in E$, define a mapping $T_{r}: E \rightarrow C$ as follows:

$$
T_{r} x=\left\{z \in C: f(z, y)+\frac{1}{r}\langle y-z, J z-J x\rangle \geq 0, \forall y \in C\right\} .
$$

Then, the following hold:

(1) $T_{r}$ is single-valued;

(2) $T_{r}$ is a firmly nonexpansive-type mapping [32], that is, for all $x, y \in E$,

$$
\left\langle T_{r} x-T_{r} y, J T_{r} x-J T_{r} y\right\rangle \leq\left\langle T_{r} x-T_{r} y, J x-J y\right\rangle
$$

(3) $F\left(T_{r}\right)=E P(f)$;

(4) $E P(f)$ is closed and convex.

Lemma 2.11 (Takahashi and Zembayashi [14]). Let $C$ be a closed convex subset of a smooth, strictly, and reflexive Banach space $E$, let $f$ be a bifucntion from $C \times C$ to $R$ satisfying (A1)-(A4), let $r>0$. Then, for all $x \in E$ and $q \in F\left(T_{r}\right)$,

$$
\phi\left(q, T_{r} x\right)+\phi\left(T_{r} x, x\right) \leq \phi(q, x)
$$

We make use of the following mapping $V$ studied in Alber [28]:

$$
V\left(x, x^{*}\right)=\|x\|^{2}-2\left\langle x, x^{*}\right\rangle+\left\|x^{*}\right\|^{2}
$$

for all $x \in E$ and $x^{*} \in E^{*}$, that is, $V\left(x, x^{*}\right)=\phi\left(x, J^{-1}\left(x^{*}\right)\right)$. 
Lemma 2.12 (Alber [28]). Let E be a reflexive, strictly convex, smooth Banach space and let $V$ be as in (2.14). Then

$$
V\left(x, x^{*}\right)+2\left\langle J^{-1}\left(x^{*}\right)-x, y^{*}\right\rangle \leq V\left(x, x^{*}+y^{*}\right)
$$

for all $x \in E$ and $x^{*}, y^{*} \in E^{*}$.

An operator $A$ of $C$ into $E^{*}$ is said to be hemicontinuous if for all $x, y \in C$, the mapping $F$ of $[0,1]$ into $E^{*}$ defined by $F(t)=A(t x+(1-t) y)$ is continuous with respect to the weak ${ }^{*}$ topology of $E^{*}$. We define by $N_{C}(v)$ the normal cone for $C$ at a point $v \in C$, that is,

$$
N_{C}(v)=\left\{x^{*} \in E^{*}:\left\langle v-y, x^{*}\right\rangle \geq 0, \forall y \in C\right\} .
$$

Theorem 2.13 (Rockafellar [33]). Let $C$ be a nonempty, closed convex subset of a Banach space $E$ and $A$ a monotone, hemicontinuous operator of $C$ into $E^{*}$. Let $T_{e} \subset E \times E^{*}$ be an operator defined as follows:

$$
T_{e} v= \begin{cases}A v+N_{C}(v), & v \in C \\ \varnothing, & \text { otherwise. }\end{cases}
$$

Then $T_{e}$ is maximal monotone and $T_{e}^{-1} 0=V I(A, C)$.

\section{Strong Convergence Theorems}

Theorem 3.1. Let $E$ be a 2-uniformly convex, uniformly smooth Banach space, let $C$ be a nonempty closed convex subset of $E$. Let $f$ be a bifunction from $C \times C$ to $R$ satisfying (A1)-(A4), let $A$ be an operator of $C$ into $E^{*}$ satisfying $(C 1)-(C 3)$, and let $T, S$ be two closed relatively quasi-nonexpansive mappings from $C$ into itself such that $F:=F(T) \cap F(S) \cap E P(f) \cap V I(A, C) \neq \varnothing$. For an initial point $x_{0} \in E$ with $x_{1}=\Pi_{C_{1}} x_{0}$ and $C_{1}=C$, define a sequence $\left\{x_{n}\right\}$ as follows:

$$
\begin{gathered}
z_{n}=\Pi_{C} J^{-1}\left(J x_{n}-\lambda_{n} A x_{n}\right), \\
y_{n}=J^{-1}\left(\alpha_{n} J x_{n}+\beta_{n} J T x_{n}+\gamma_{n} J S z_{n}\right), \\
u_{n} \in C \text { such that } f\left(u_{n}, y\right)+\frac{1}{r_{n}}\left\langle y-u_{n} J u_{n}-J y_{n}\right\rangle \geq 0, \quad \forall y \in C, \\
C_{n+1}=\left\{z \in C_{n}: \phi\left(z, u_{n}\right) \leq \phi\left(z, x_{n}\right)\right\}, \\
x_{n+1}=\prod_{C_{n+1}} x_{0}, \quad \forall n \geq 1,
\end{gathered}
$$

where $J$ is the duality mapping on E. Assume that $\left\{\alpha_{n}\right\},\left\{\beta_{n}\right\}$, and $\left\{\gamma_{n}\right\}$ are sequences in $[0,1]$ satisfying the restrictions:

(B1) $\alpha_{n}+\beta_{n}+\gamma_{n}=1$;

(B2) $\liminf _{n \rightarrow \infty} \alpha_{n} \beta_{n}>0, \liminf _{n \rightarrow \infty} \alpha_{n} \gamma_{n}>0$; 
(B3) $\left\{r_{n}\right\} \subset[s, \infty)$ for some $s>0$;

(B4) $\left\{\lambda_{n}\right\} \subset[a, b]$ for some $a, b$ with $0<a<b<c^{2} \alpha / 2$, where $1 / c$ is the 2-uniformly convexity constant of $E$.

Then, $\left\{x_{n}\right\}$ and $\left\{u_{n}\right\}$ converge strongly to $q=\Pi_{F} x_{0}$.

Proof. We divide the proof into eight steps.

Step 1. Show that $\Pi_{F} x_{0}$ and $\Pi_{C_{n+1}} x_{0}$ are well defined.

It is obvious that $\operatorname{VI}(A, C)$ is a closed convex subset of $C$. By Lemma 2.7, we know that $F(T) \cap F(S)$ is closed and convex. From Lemma $2.10(4)$, we also have $E P(f)$ is closed and convex. Hence $F:=F(T) \cap F(S) \cap E P(f) \cap V I(A, C)$ is a nonempty, closed, and convex subset of $C$; consequently, $\Pi_{F} x_{0}$ is well defined.

Clearly, $C_{1}=C$ is closed and convex. Suppose that $C_{k}$ is closed and convex for $k \in N$. For all $z \in C_{k}$, we know $\phi\left(z, y_{k}\right) \leq \phi\left(z, x_{k}\right)$ is equivalent to

$$
2\left\langle z, J x_{k}-J y_{k}\right\rangle \leq\left\|x_{k}\right\|^{2}-\left\|y_{k}\right\|^{2}
$$

So, $C_{k+1}$ is closed and convex. By induction, $C_{n}$ is closed and convex for all $n \geq 1$. This shows that $\Pi_{C_{n+1}} x_{0}$ is well-defined.

Step 2. Show that $F \subset C_{n}$ for all $n \in N$.

Put $v_{n}=J^{-1}\left(J x_{n}-\lambda_{n} A x_{n}\right)$. First, we observe that $u_{n}=T_{r_{n}} y_{n}$ for all $n \geq 1$ and $F \subset C_{1}=$ $C$. Suppose $F \subset C_{k}$ for $k \in N$. Then, for all $u \in F$, we know from Lemma 2.6 and Lemma 2.12 that

$$
\begin{aligned}
\phi\left(u, z_{k}\right) & =\phi\left(u, \Pi_{C} v_{k}\right) \\
& \leq \phi\left(u, v_{k}\right) \\
& =\phi\left(u, J^{-1}\left(J x_{k}-\lambda_{k} A x_{k}\right)\right) \\
& =V\left(u, J x_{k}-\lambda_{k} A x_{k}\right) \\
& \leq V\left(u,\left(J x_{k}-\lambda_{k} A x_{k}\right)+\lambda_{k} A x_{k}\right)-2\left\langle J^{-1}\left(J x_{k}-\lambda_{k} A x_{k}\right)-u, \lambda_{k} A x_{k}\right\rangle \\
& =V\left(u, J x_{k}\right)-2 \lambda_{k}\left\langle v_{k}-u, A x_{k}\right\rangle \\
& =\phi\left(u, x_{k}\right)-2 \lambda_{k}\left\langle x_{k}-u, A x_{k}\right\rangle+2\left\langle v_{k}-x_{k},-\lambda_{k} A x_{k}\right\rangle .
\end{aligned}
$$

Since $u \in V I(A, C)$ and from $(C 1)$, we have

$$
\begin{aligned}
-2 \lambda_{k}\left\langle x_{k}-u, A x_{k}\right\rangle & =-2 \lambda_{k}\left\langle x_{k}-u, A x_{k}-A u\right\rangle-2 \lambda_{k}\left\langle x_{k}-u, A u\right\rangle \\
& \leq-2 \alpha \lambda_{k}\left\|A x_{k}-A u\right\|^{2} .
\end{aligned}
$$


Fixed Point Theory and Applications

From Lemma 2.1 and (C3), we obtain

$$
\begin{aligned}
2\left\langle v_{k}-x_{k},-\lambda_{k} A x_{k}\right\rangle & =2\left\langle J^{-1}\left(J x_{k}-\lambda_{k} A x_{k}\right)-J^{-1}\left(J x_{k}\right),-\lambda_{k} A x_{k}\right\rangle \\
& \leq 2\left\|J^{-1}\left(J x_{k}-\lambda_{k} A x_{k}\right)-J^{-1}\left(J x_{k}\right)\right\|\left\|\lambda_{k} A x_{k}\right\| \\
& \leq \frac{4}{c^{2}}\left\|J J^{-1}\left(J x_{k}-\lambda_{k} A x_{k}\right)-J J^{-1}\left(J x_{k}\right)\right\|\left\|\lambda_{k} A x_{k}\right\| \\
& =\frac{4}{c^{2}}\left\|\left(J x_{k}-\lambda_{k} A x_{k}\right)-\left(J x_{k}\right)\right\|\left\|\lambda_{k} A x_{k}\right\| \\
& =\frac{4}{c^{2}} \lambda_{k}^{2}\left\|A x_{k}\right\|^{2} \\
& \leq \frac{4}{c^{2}} \lambda_{k}^{2}\left\|A x_{k}-A u\right\|^{2} .
\end{aligned}
$$

Replacing (3.4) and (3.5) into (3.3), we get

$$
\phi\left(u, z_{k}\right) \leq \phi\left(u, x_{k}\right)+2 \lambda_{k}\left(\frac{2}{c^{2}} \lambda_{k}-\alpha\right)\left\|A x_{k}-A u\right\|^{2} \leq \phi\left(u, x_{k}\right) .
$$

By the convexity of $\|\cdot\|^{2}$, for each $u \in F \subset C_{k}$, we obtain

$$
\begin{aligned}
\phi\left(u, u_{k}\right)= & \phi\left(u, T_{r_{k}} y_{k}\right) \\
\leq & \phi\left(u, y_{k}\right) \\
= & \phi\left(u, J^{-1}\left(\alpha_{k} J x_{k}+\beta_{k} J T x_{k}+\gamma_{k} J S z_{k}\right)\right) \\
= & \|u\|^{2}-2 \alpha_{k}\left\langle u, J x_{k}\right\rangle-2 \beta_{k}\left\langle u, J T x_{k}\right\rangle-2 \gamma_{k}\left\langle u, J S z_{k}\right\rangle \\
& +\left\|\alpha_{k} J x_{k}+\beta_{k} J T x_{k}+\gamma_{k} J S z_{k}\right\|^{2} \\
\leq & \|u\|^{2}-2 \alpha_{k}\left\langle u, J x_{k}\right\rangle-2 \beta_{k}\left\langle u, J T x_{k}\right\rangle-2 \gamma_{k}\left\langle u, J S z_{k}\right\rangle \\
& +\alpha_{k}\left\|J x_{k}\right\|^{2}+\beta_{k}\left\|J T x_{k}\right\|^{2}+\gamma_{k}\left\|J S z_{k}\right\|^{2} \\
= & \alpha_{k} \phi\left(u, x_{k}\right)+\beta_{k} \phi\left(u, T x_{k}\right)+\gamma_{k} \phi\left(u, S z_{k}\right) \\
\leq & \alpha_{k} \phi\left(u, x_{k}\right)+\beta_{k} \phi\left(u, x_{k}\right)+\gamma_{k} \phi\left(u, z_{k}\right) \\
\leq & \phi\left(u, x_{k}\right) .
\end{aligned}
$$

This shows that $u \in C_{k+1}$; consequently, $F \subset C_{k+1}$. Hence $F \subset C_{n}$ for all $n \geq 1$.

Step 3. Show that $\lim _{n \rightarrow \infty} \phi\left(x_{n}, x_{0}\right)$ exists.

From $x_{n}=\Pi_{C_{n}} x_{0}$ and $x_{n+1}=\Pi_{C_{n+1}} x_{0} \in C_{n+1} \subset C_{n}$, we have

$$
\phi\left(x_{n}, x_{0}\right) \leq \phi\left(x_{n+1}, x_{0}\right), \quad \forall n \geq 1 .
$$


From Lemma 2.6, we have

$$
\phi\left(x_{n}, x_{0}\right)=\phi\left(\Pi_{C_{n}} x_{0}, x_{0}\right) \leq \phi\left(u, x_{0}\right)-\phi\left(u, x_{n}\right) \leq \phi\left(u, x_{0}\right) .
$$

Combining (3.8) and (3.9), we obtain that $\lim _{n \rightarrow \infty} \phi\left(x_{n}, x_{0}\right)$ exists.

Step 4. Show that $\left\{x_{n}\right\}$ is a Cauchy sequence in $C$.

Since $x_{m}=\prod_{C_{m}} x_{0} \in C_{m} \subset C_{n}$ for $m>n$, by Lemma 2.6, we also have

$$
\begin{aligned}
\phi\left(x_{m}, x_{n}\right) & =\phi\left(x_{m}, \Pi_{C_{n}} x_{0}\right) \\
& \leq \phi\left(x_{m}, x_{0}\right)-\phi\left(\Pi_{C_{n}} x_{0}, x_{0}\right) \\
& =\phi\left(x_{m}, x_{0}\right)-\phi\left(x_{n}, x_{0}\right) .
\end{aligned}
$$

Taking $m, n \rightarrow \infty$, we obtain that $\phi\left(x_{m}, x_{n}\right) \rightarrow 0$. From Lemma 2.4, we have $\left\|x_{m}-x_{n}\right\| \rightarrow 0$. Hence $\left\{x_{n}\right\}$ is a Cauchy sequence. By the completeness of $E$ and the closedness of $C$, one can assume that $x_{n} \rightarrow q \in C$ as $n \rightarrow \infty$. Further, we obtain

$$
\lim _{n \rightarrow \infty} \phi\left(x_{n+1}, x_{n}\right)=0
$$

Since $x_{n+1}=\Pi_{C_{n+1}} x_{0} \in C_{n+1}$, we have

$$
\phi\left(x_{n+1}, u_{n}\right) \leq \phi\left(x_{n+1}, x_{n}\right) \longrightarrow 0,
$$

as $n \rightarrow \infty$. Applying Lemma 2.4 to (3.11) and (3.12), we get

$$
\lim _{n \rightarrow \infty}\left\|u_{n}-x_{n}\right\|=0
$$

This implies that $u_{n} \rightarrow q$ as $n \rightarrow \infty$. Since $J$ is uniformly norm-to-norm continuous on bounded subsets of $E$, we also obtain

$$
\lim _{n \rightarrow \infty}\left\|J u_{n}-J x_{n}\right\|=0
$$

Step 5. Show that $x_{n} \rightarrow q \in F(T) \cap F(S)$. 
Fixed Point Theory and Applications

Let $r=\sup _{n \geq 1}\left\{\left\|x_{n}\right\|,\left\|T x_{n}\right\|,\left\|S z_{n}\right\|\right\}$. From (3.6) and Lemma 2.8, we know that there exists a continuous strictly increasing convex function $g:[0, \infty) \rightarrow[0, \infty)$ with $g(0)=0$ such that

$$
\begin{aligned}
\phi\left(u, u_{n}\right)= & \phi\left(u, T_{r_{n}} y_{n}\right) \\
\leq & \phi\left(u, y_{n}\right) \\
= & \phi\left(u, J^{-1}\left(\alpha_{n} J x_{n}+\beta_{n} J T x_{n}+\gamma_{n} J S z_{n}\right)\right) \\
= & \|u\|^{2}-2 \alpha_{n}\left\langle u, J x_{n}\right\rangle-2 \beta_{n}\left\langle u, J T x_{n}\right\rangle-2 \gamma_{n}\left\langle u, J S z_{n}\right\rangle \\
& +\left\|\alpha_{n} J x_{n}+\beta_{n} J T x_{n}+\gamma_{n} J S z_{n}\right\|^{2} \\
\leq & \|u\|^{2}-2 \alpha_{n}\left\langle u, J x_{n}\right\rangle-2 \beta_{n}\left\langle u, J T x_{n}\right\rangle-2 \gamma_{n}\left\langle u, J S z_{n}\right\rangle \\
& +\alpha_{n}\left\|J x_{n}\right\|^{2}+\beta_{n}\left\|J T x_{n}\right\|^{2}+\gamma_{n}\left\|J S z_{n}\right\|^{2} \\
& -\alpha_{n} \beta_{n} g\left(\left\|J x_{n}-J T x_{n}\right\|\right) \\
= & \alpha_{n} \phi\left(u, x_{n}\right)+\beta_{n} \phi\left(u, T x_{n}\right)+\gamma_{n} \phi\left(u, S z_{n}\right) \\
& -\alpha_{n} \beta_{n} g\left(\left\|J x_{n}-J T x_{n}\right\|\right) \\
\leq & \phi\left(u, x_{n}\right)+2 \gamma_{n} \lambda_{n}\left(\frac{2}{c^{2}} \lambda_{n}-\alpha\right)\left\|A x_{n}-A u\right\|^{2} \\
& -\alpha_{n} \beta_{n} g\left(\left\|J x_{n}-J T x_{n}\right\|\right) .
\end{aligned}
$$

This implies that

$$
\begin{aligned}
\alpha_{n} \beta_{n} g\left(\left\|J x_{n}-J T x_{n}\right\|\right) & \leq \phi\left(u, x_{n}\right)-\phi\left(u, u_{n}\right) \\
& =\left\|x_{n}\right\|^{2}-\left\|u_{n}\right\|^{2}-2\left\langle u, J x_{n}-J u_{n}\right\rangle \\
& \leq\left\|x_{n}-u_{n}\right\|\left(\left\|x_{n}\right\|+\left\|u_{n}\right\|\right)+2\|u\|\left\|J x_{n}-J u_{n}\right\| .
\end{aligned}
$$

It follows from (3.13), (3.14), and (B2) that

$$
\lim _{n \rightarrow \infty} g\left(\left\|J x_{n}-J T x_{n}\right\|\right)=0
$$

By the property of $g$, we also obtain that

$$
\lim _{n \rightarrow \infty}\left\|J x_{n}-J T x_{n}\right\|=0
$$

Since $J$ is uniformly norm-to-norm continuous on bounded sets, so is $J^{-1}$. Then

$$
\lim _{n \rightarrow \infty}\left\|x_{n}-T x_{n}\right\|=\lim _{n \rightarrow \infty}\left\|J^{-1}\left(J x_{n}\right)-J^{-1}\left(J T x_{n}\right)\right\|=0 .
$$


In the same manner, we can show that

$$
\lim _{n \rightarrow \infty}\left\|x_{n}-S z_{n}\right\|=0
$$

Again, by (3.15), we have

$$
2 a\left(\alpha-\frac{2}{c^{2}} b\right)\left\|A x_{n}-A u\right\|^{2} \leq \frac{1}{\gamma_{n}}\left(\phi\left(u, x_{n}\right)-\phi\left(u, u_{n}\right)\right),
$$

which yields that

$$
\lim _{n \rightarrow \infty}\left\|A x_{n}-A u\right\|=0 .
$$

From Lemma 2.6, Lemma 2.12, and (3.5), we have

$$
\begin{aligned}
\phi\left(x_{n}, z_{n}\right)= & \phi\left(x_{n}, \Pi_{C} v_{n}\right) \\
\leq & \phi\left(x_{n}, v_{n}\right) \\
= & \phi\left(x_{n}, J^{-1}\left(J x_{n}-\lambda_{n} A x_{n}\right)\right) \\
= & V\left(x_{n}, J x_{n}-\lambda_{n} A x_{n}\right) \\
\leq & V\left(x_{n},\left(J x_{n}-\lambda_{n} A x_{n}\right)+\lambda_{n} A x_{n}\right) \\
& -2\left\langle J^{-1}\left(J x_{n}-\lambda_{n} A x_{n}\right)-x_{n}, \lambda_{n} A x_{n}\right\rangle \\
= & \phi\left(x_{n}, x_{n}\right)+2\left\langle v_{n}-x_{n},-\lambda_{n} A x_{n}\right\rangle \\
= & 2\left\langle v_{n}-x_{n},-\lambda_{n} A x_{n}\right\rangle \leq \frac{4}{c^{2}} b^{2}\left\|A x_{n}-A u\right\|^{2} .
\end{aligned}
$$

It follows from Lemma 2.4 and (3.22) that

$$
\lim _{n \rightarrow \infty}\left\|x_{n}-z_{n}\right\|=0
$$

Hence $z_{n} \rightarrow q$ as $n \rightarrow \infty$ and

$$
\lim _{n \rightarrow \infty}\left\|J x_{n}-J z_{n}\right\|=0 .
$$

Combining (3.20) and (3.24), we also obtain

$$
\lim _{n \rightarrow \infty}\left\|S z_{n}-z_{n}\right\|=0
$$

From (3.19), (3.26) and by the closedness of $T$ and $S$, we get $q \in F(T) \cap F(S)$. 
Step 6. Show that $x_{n} \rightarrow q \in E P(f)$.

From (3.15), we see

$$
\phi\left(u, y_{n}\right) \leq \phi\left(u, x_{n}\right)
$$

From (3.16), we observe

$$
\lim _{n \rightarrow \infty} \phi\left(u, x_{n}\right)-\phi\left(u, u_{n}\right)=0
$$

Note that $u_{n}=T_{r_{n}} y_{n}$. From (3.27) and Lemma 2.11, we have

$$
\begin{aligned}
\phi\left(u_{n}, y_{n}\right) & =\phi\left(T_{r_{n}} y_{n}, y_{n}\right) \\
& \leq \phi\left(u, y_{n}\right)-\phi\left(u, T_{r_{n}} y_{n}\right) \\
& \leq \phi\left(u, x_{n}\right)-\phi\left(u, T_{r_{n}} y_{n}\right) \\
& =\phi\left(u, x_{n}\right)-\phi\left(u, u_{n}\right) .
\end{aligned}
$$

From (3.28), we get $\lim _{n \rightarrow \infty} \phi\left(u_{n}, y_{n}\right)=0$. By Lemma 2.4, we obtain

$$
\left\|u_{n}-y_{n}\right\| \longrightarrow 0
$$

as $n \rightarrow \infty$. Since $r_{n} \geq s$, we have

$$
\frac{\left\|J u_{n}-J y_{n}\right\|}{r_{n}} \longrightarrow 0
$$

as $n \rightarrow \infty$. From $u_{n}=T_{r_{n}} y_{n}$ we have

$$
f\left(u_{n}, y\right)+\frac{1}{r_{n}}\left\langle y-u_{n}, J u_{n}-J y_{n}\right\rangle \geq 0, \quad \forall y \in C
$$

By (A2), we have

$$
\begin{aligned}
\left\|y-u_{n}\right\| \frac{\left\|J u_{n}-J y_{n}\right\|}{r_{n}} & \geq \frac{1}{r_{n}}\left\langle y-u_{n}, J u_{n}-J y_{n}\right\rangle \\
& \geq-f\left(u_{n}, y\right) \\
& \geq f\left(y, u_{n}\right), \quad \forall y \in C .
\end{aligned}
$$

From (A4) and $u_{n} \rightarrow q$, we get $f(y, q) \leq 0$ for all $y \in C$. For $0<t<1$ and $y \in C$. Define $y_{t}=t y+(1-t) q$, then $y_{t} \in C$, which implies that $f\left(y_{t}, q\right) \leq 0$. From (A1), we obtain that $0=f\left(y_{t}, y_{t}\right) \leq t f\left(y_{t}, y\right)+(1-t) f\left(y_{t}, q\right) \leq t f\left(y_{t}, y\right)$. Thus, $f\left(y_{t}, y\right) \geq 0$. From (A3), we have $f(q, y) \geq 0$ for all $y \in C$. Hence $q \in E P(f)$. 
Step 7. Show that $x_{n} \rightarrow q \in V I(A, C)$.

Define $T_{e} \subset E \times E^{*}$ be as in (2.17). By Theorem 2.13, $T_{e}$ is maximal monotone and $T_{e}^{-1} 0=V I(A, C)$. Let $(v, w) \in G\left(T_{e}\right)$. Since $w \in T_{e} v=A v+N_{C}(v)$, we get $w-A v \in N_{C}(v)$. From $z_{n} \in C$, we have

$$
\left\langle v-z_{n}, w-A v\right\rangle \geq 0
$$

On the other hand, since $z_{n}=\Pi_{C} J^{-1}\left(J x_{n}-\lambda_{n} A x_{n}\right)$. Then, by Lemma 2.5, we have $\left\langle v-z_{n}, J z_{n}-\right.$ $\left.\left(J x_{n}-\lambda_{n} A x_{n}\right)\right\rangle \geq 0$ and thus

$$
\left\langle v-z_{n}, \frac{J x_{n}-J z_{n}}{\lambda_{n}}-A x_{n}\right\rangle \leq 0
$$

It follows from (3.34) and (3.35) that

$$
\begin{aligned}
\left\langle v-z_{n}, w\right\rangle \geq & \left\langle v-z_{n}, A v\right\rangle \\
\geq & \left\langle v-z_{n}, A v\right\rangle+\left\langle v-z_{n}, \frac{J x_{n}-J z_{n}}{\lambda_{n}}-A x_{n}\right\rangle \\
= & \left\langle v-z_{n}, A v-A x_{n}\right\rangle+\left\langle v-z_{n}, \frac{J x_{n}-J z_{n}}{\lambda_{n}}\right\rangle \\
= & \left\langle v-z_{n}, A v-A z_{n}\right\rangle+\left\langle v-z_{n}, A z_{n}-A x_{n}\right\rangle \\
& +\left\langle v-z_{n}, \frac{J x_{n}-J z_{n}}{\lambda_{n}}\right\rangle \\
\geq & -\left\|v-z_{n}\right\| \frac{\left\|z_{n}-x_{n}\right\|}{\alpha}-\left\|v-z_{n}\right\| \frac{\left\|J x_{n}-J z_{n}\right\|}{a} \\
\geq & -M\left(\frac{\left\|z_{n}-x_{n}\right\|}{\alpha}+\frac{\left\|J x_{n}-J z_{n}\right\|}{a}\right),
\end{aligned}
$$

where $M=\sup _{n \geq 1}\left\{\left\|v-z_{n}\right\|\right\}$. By taking the limit as $n \rightarrow \infty$ and from (3.24) and (3.25), we obtain $\langle v-q, w\rangle \geq 0$. By the maximality of $T_{e}$, we have $q \in T_{e}^{-1} 0$ and hence $q \in V I(A, C)$.

Step 8. Show that $q=\Pi_{F} x_{0}$.

From $x_{n}=\Pi_{C_{n}} x_{0}$, we have

$$
\left\langle J x_{0}-J x_{n}, x_{n}-z\right\rangle \geq 0, \quad \forall z \in C_{n}
$$

Since $F \subset C_{n}$, we also have

$$
\left\langle J x_{0}-J x_{n}, x_{n}-u\right\rangle \geq 0, \quad \forall u \in F .
$$

By taking limit in (3.38), we obtain that

$$
\left\langle J x_{0}-J q, q-u\right\rangle \geq 0, \quad \forall u \in F .
$$


By Lemma 2.5, we can conclude that $q=\prod_{F} x_{0}$. Furthermore, it is easy to see that $u_{n} \rightarrow q$ as $n \rightarrow \infty$. This completes the proof.

As a direct consequence of Theorem 3.1, we obtain the following results.

Corollary 3.2. Let $E$ be a 2-uniformly convex and uniformly smooth Banach space, and let $C$ be a nonempty closed convex subset of $E$. Let $f$ be a bifunction from $C \times C$ to $R$ satisfying $(A 1)-(A 4)$ and let $T$ be a closed relatively quasi-nonexpansive mapping from $C$ into itself such that $F(T) \cap E P(f) \neq \varnothing$. Assume that $\left\{\alpha_{n}\right\} \subset[0,1]$ satisfies $\liminf _{n \rightarrow \infty} \alpha_{n}\left(1-\alpha_{n}\right)>0$ and $\left\{r_{n}\right\} \subset[s, \infty)$ for some $s>0$. Then the sequence $\left\{x_{n}\right\}$ generated by (1.7) converges strongly to $q=\prod_{F(T) \cap E P(f)} x_{0}$.

Proof. Putting $S=T$ and $A \equiv 0$ in Theorem 3.1, we obtain the result.

Remark 3.3. If $A \equiv 0$ in Theorem 3.1, then Theorem 3.1 reduces to Theorem 3.1 of Qin et al. [6].

Remark 3.4. Corollary 3.2 improves Theorem 3.1 of Takahashi and Zembayashi [5] from the class of relatively nonexpansive mappings to the class of relatively quasi-nonexpansive mappings, that is, we relax the strong restriction: $F(\widehat{T})=F(T)$. Further, the algorithm in Corollary 3.2 is also simpler to compute than the one given in [14].

\section{Applications}

Next, we consider the problem of finding a zero point of an inverse-strongly monotone operator of $E$ into $E^{*}$. Assume that $A$ satisfies the conditions:

(D1) $A$ is $\alpha$-inverse-strongly monotone,

(D2) $A^{-1} 0=\{u \in E: \quad A u=0\} \neq \varnothing$.

Theorem 4.1. Let E be a 2-uniformly convex, uniformly smooth Banach space. Let $f$ be a bifunction from $E \times E$ to $R$ satisfying (A1)-(A4), let $A$ be an operator of $E$ into $E^{*}$ satisfying (D1) and (D2), and let $T, S$ be two closed relatively quasi-nonexpansive mappings from $E$ into itself such that $F:=$ $F(T) \cap F(S) \cap E P(f) \cap A^{-1} 0 \neq \varnothing$. For an initial point $x_{0} \in E$ with $x_{1}=\Pi_{C_{1}} x_{0}$ and $C_{1}=E$, define a sequence $\left\{x_{n}\right\}$ as follows:

$$
\begin{gathered}
z_{n}=J^{-1}\left(J x_{n}-\lambda_{n} A x_{n}\right), \\
y_{n}=J^{-1}\left(\alpha_{n} J x_{n}+\beta_{n} J T x_{n}+\gamma_{n} J S z_{n}\right), \\
u_{n} \in E \quad \text { such that } f\left(u_{n}, y\right)+\frac{1}{r_{n}}\left\langle y-u_{n}, J u_{n}-J y_{n}\right\rangle \geq 0, \quad \forall y \in E, \\
C_{n+1}=\left\{z \in C_{n}: \phi\left(z, u_{n}\right) \leq \phi\left(z, x_{n}\right)\right\}, \\
x_{n+1}=\prod_{C_{n+1}} x_{0}, \quad \forall n \geq 1,
\end{gathered}
$$

where $J$ is the duality mapping on E. Assume that $\left\{\alpha_{n}\right\},\left\{\beta_{n}\right\}$, and $\left\{\gamma_{n}\right\}$ are sequences in $[0,1]$ satisfying the conditions (B1)-(B4) of Theorem 3.1.

Then, $\left\{x_{n}\right\}$ and $\left\{u_{n}\right\}$ converge strongly to $q=\Pi_{F} x_{0}$. 
Proof. Putting $C=E$ in Theorem 3.1, we have $\Pi_{E}=I$. We also have $\operatorname{VI}(A, E)=A^{-1} 0$ and then the condition (C3) of Theorem 3.1 holds for all $y \in E$ and $u \in A^{-1} 0$. So, we obtain the result.

Let $K$ be a nonempty, closed convex cone in $E, A$ an operator of $K$ into $E^{*}$. We define its polar in $E^{*}$ to be the set

$$
K^{*}=\left\{y^{*} \in E^{*}:\left\langle x, y^{*}\right\rangle \geq 0, \forall x \in K\right\}
$$

Then the element $u \in K$ is called a solution of the complementarity problem if

$$
A u \in K^{*}, \quad\langle u, A u\rangle=0 .
$$

The set of solutions of the complementarity problem is denoted by $C(K, A)$.

Assume that $A$ is an operator satisfying the conditions:

(E1) $A$ is $\alpha$-inverse-strongly monotone,

(E2) $C(K, A) \neq \varnothing$,

(E3) $\|A y\| \leq\|A y-A u\|$ for all $y \in K$ and $u \in C(K, A)$.

Theorem 4.2. Let $E$ be a 2-uniformly convex, uniformly smooth Banach space, and $K$ a nonempty, closed convex cone in $E$. Let $f$ be a bifunction from $K \times K$ to $R$ satisfying $(A 1)-(A 4)$, let $A$ be an operator of $K$ into $E^{*}$ satisfying (E1)-(E3), and let $T, S$ be two closed relatively quasi-nonexpansive mappings from $K$ into itself such that $F:=F(T) \cap F(S) \cap E P(f) \cap C(K, A) \neq \varnothing$. For an initial point $x_{0} \in E$ with $x_{1}=\Pi_{C_{1}} x_{0}$ and $C_{1}=K$, define a sequence $\left\{x_{n}\right\}$ as follows:

$$
\begin{gathered}
z_{n}=\Pi_{K} J^{-1}\left(J x_{n}-\lambda_{n} A x_{n}\right), \\
y_{n}=J^{-1}\left(\alpha_{n} J x_{n}+\beta_{n} J T x_{n}+\gamma_{n} J S z_{n}\right), \\
u_{n} \in K \quad \text { such that } f\left(u_{n}, y\right)+\frac{1}{r_{n}}\left\langle y-u_{n} J u_{n}-J y_{n}\right\rangle \geq 0, \quad \forall y \in K, \\
C_{n+1}=\left\{z \in C_{n}: \phi\left(z, u_{n}\right) \leq \phi\left(z, x_{n}\right)\right\}, \\
x_{n+1}=\prod_{C_{n+1}} x_{0}, \quad \forall n \geq 1,
\end{gathered}
$$

where $J$ is the duality mapping on E. Assume that $\left\{\alpha_{n}\right\},\left\{\beta_{n}\right\}$ and $\left\{\gamma_{n}\right\}$ are sequences in $[0,1]$ satisfying the conditions (B1)-(B4) of Theorem 3.1.

Then, $\left\{x_{n}\right\}$ and $\left\{u_{n}\right\}$ converge strongly to $q=\Pi_{F} x_{0}$.

Proof. From [20, Lemma 7.1.1], we have $\operatorname{VI}(K, A)=C(K, A)$. Hence, we obtain the result.

\section{Acknowledgments}

The author would like to thank Professor Suthep Suantai and the referee for the valuable suggestions on the manuscript. The author was supported by the Commission on Higher Education and the Thailand Research Fund. 


\section{References}

[1] H. Iiduka and W. Takahashi, "Weak convergence of a projection algorithm for variational inequalities in a Banach space," Journal of Mathematical Analysis and Applications, vol. 339, no. 1, pp. 668-679, 2008.

[2] F. E. Browder and W. V. Petryshyn, "Construction of fixed points of nonlinear mappings in Hilbert space," Journal of Mathematical Analysis and Applications, vol. 20, no. 2, pp. 197-228, 1967.

[3] H. Iiduka, W. Takahashi, and M. Toyoda, "Approximation of solutions of variational inequalities for monotone mappings," Panamerican Mathematical Journal, vol. 14, no. 2, pp. 49-61, 2004.

[4] F. Liu and M. Z. Nashed, "Regularization of nonlinear ill-posed variational inequalities and convergence rates," Set-Valued Analysis, vol. 6, no. 4, pp. 313-344, 1998.

[5] W. Takahashi and K. Zembayashi, "Strong convergence theorem by a new hybrid method for equilibrium problems and relatively nonexpansive mappings," Fixed Point Theory and Applications, vol. 2008, Article ID 528476, 11 pages, 2008.

[6] X. Qin, Y. J. Cho, and S. M. Kang, "Convergence theorems of common elements for equilibrium problems and fixed point problems in Banach spaces," Journal of Computational and Applied Mathematics, vol. 225, no. 1, pp. 20-30, 2009.

[7] E. Blum and W. Oettli, "From optimization and variational inequalities to equilibrium problems," The Mathematics Student, vol. 63, no. 1-4, pp. 123-145, 1994.

[8] P. L. Combettes and S. A. Hirstoaga, "Equilibrium programming in Hilbert spaces," Journal of Nonlinear and Convex Analysis, vol. 6, no. 1, pp. 117-136, 2005.

[9] S. Matsushita and W. Takahashi, "A strong convergence theorem for relatively nonexpansive mappings in a Banach space," Journal of Approximation Theory, vol. 134, no. 2, pp. 257-266, 2005.

[10] S. Matsushita and W. Takahashi, "Weak and strong convergence theorems for relatively nonexpansive mappings in Banach spaces," Fixed Point Theory and Applications, vol. 2004, no. 1, pp. 37-47, 2004.

[11] S. Plubtieng and K. Ungchittrakool, "Strong convergence theorems for a common fixed point of two relatively nonexpansive mappings in a Banach space," Journal of Approximation Theory, vol. 149, no. 2, pp. 103-115, 2007.

[12] A. Tada and W. Takahashi, "Weak and strong convergence theorems for a nonexpansive mapping and an equilibrium problem," Journal of Optimization Theory and Applications, vol. 133, no. 3, pp. 359-370, 2007.

[13] S. Takahashi and W. Takahashi, "Strong convergence theorem for a generalized equilibrium problem and a nonexpansive mapping in a Hilbert space," Nonlinear Analysis: Theory, Methods E Applications, vol. 69, no. 3, pp. 1025-1033, 2008.

[14] W. Takahashi and K. Zembayashi, "Strong and weak convergence theorems for equilibrium problems and relatively nonexpansive mappings in Banach spaces," Nonlinear Analysis: Theory, Methods $\mathcal{E}$ Applications, vol. 70, no. 1, pp. 45-57, 2009.

[15] K. Wattanawitoon and P. Kumam, "Strong convergence theorems by a new hybrid projection algorithm for fixed point problems and equilibrium problems of two relatively quasi-nonexpansive mappings," Nonlinear Analysis: Hybrid Systems, vol. 3, no. 1, pp. 11-20, 2009.

[16] Y. Yao, M. A. Noor, and Y.-C. Liou, "On iterative methods for equilibrium problems," Nonlinear Analysis: Theory, Methods E Applications, vol. 70, no. 1, pp. 497-509, 2009.

[17] K. Ball, E. A. Carlen, and E. H. Lieb, "Sharp uniform convexity and smoothness inequalities for trace norms," Inventiones Mathematicae, vol. 115, no. 3, pp. 463-482, 1994.

[18] B. Beauzamy, Introduction to Banach Spaces and Their Geometry, vol. 68 of North-Holland Mathematics Studies, North-Holland, Amsterdam, The Netherlands, 2nd edition, 1985.

[19] Y. Takahashi, K. Hashimoto, and M. Kato, "On sharp uniform convexity, smoothness, and strong type, cotype inequalities," Journal of Nonlinear and Convex Analysis, vol. 3, no. 2, pp. 267-281, 2002.

[20] W. Takahashi, Nonlinear Functional Analysis, Fixed Point Theory and Its Applications, Yokohama, Yokohama, Japan, 2000.

[21] W. Takahashi, Convex Analysis and Approximation of Fixed Points, vol. 2 of Mathematical Analysis Series, Yokohama, Yokohama, Japan, 2000.

[22] C. Zălinescu, "On uniformly convex functions," Journal of Mathematical Analysis and Applications, vol. 95, no. 2, pp. 344-374, 1983.

[23] S. Reich, "Weak convergence theorems for nonexpansive mappings in Banach spaces," Journal of Mathematical Analysis and Applications, vol. 67, no. 2, pp. 274-276, 1979. 
[24] S. Reich, "A weak convergence theorem for the alternating method with Bregman distances," in Theory and Applications of Nonlinear Operators of Accretive and Monotone Type, A. G. Kartsatos, Ed., vol. 178 of Lecture Notes in Pure and Applied Mathematics, pp. 313-318, Marcel Dekker, New York, NY, USA, 1996.

[25] D. Butnariu, S. Reich, and A. J. Zaslavski, "Asymptotic behavior of relatively nonexpansive operators in Banach spaces," Journal of Applied Analysis, vol. 7, no. 2, pp. 151-174, 2001.

[26] Y. Censor and S. Reich, "Iterations of paracontractions and firmly nonexpansive operators with applications to feasibility and optimization," Optimization, vol. 37, no. 4, pp. 323-339, 1996.

[27] S. Kamimura and W. Takahashi, "Strong convergence of a proximal-type algorithm in a Banach space," SIAM Journal on Optimization, vol. 13, no. 3, pp. 938-945, 2002.

[28] Ya. I. Alber, "Metric and generalized projection operators in Banach spaces: properties and applications," in Theory and Applications of Nonlinear Operators of Accretive and Monotone Type, A. G. Kartsatos, Ed., vol. 178 of Lecture Notes in Pure and Applied Mathematics, pp. 15-50, Marcel Dekker, New York, NY, USA, 1996.

[29] Ya. I. Alber and S. Reich, "An iterative method for solving a class of nonlinear operator equations in Banach spaces," Panamerican Mathematical Journal, vol. 4, no. 2, pp. 39-54, 1994.

[30] I. Cioranescu, Geometry of Banach Spaces, Duality Mappings and Nonlinear Problems, vol. 62 of Mathematics and Its Applications, Kluwer Academic Publishers, Dordrecht, The Netherlands, 1990.

[31] Y. J. Cho, H. Zhou, and G. Guo, "Weak and strong convergence theorems for three-step iterations with errors for asymptotically nonexpansive mappings," Computers $\mathcal{E}$ Mathematics with Applications, vol. 47, no. 4-5, pp. 707-717, 2004.

[32] F. Kohsaka and W. Takahashi, "Existence and approximation of fixed points of firmly nonexpansivetype mappings in Banach spaces," SIAM Journal on Optimization, vol. 19, no. 2, pp. 824-835, 2008.

[33] R. T. Rockafellar, "On the maximality of sums of nonlinear monotone operators," Transactions of the American Mathematical Society, vol. 149, no. 1, pp. 75-88, 1970. 